\title{
Effect of allelopathy on plant performance: a meta-analysis
}

\author{
Zhijie Zhang,' (D) Yanjie \\ Liu, $^{2 *}$ (D) Ling Yuan, ${ }^{3}$ Ewald \\ Weber ${ }^{4}$ and Mark van \\ Kleunen ${ }^{1,3}$
}

\begin{abstract}
Allelopathy (i.e. chemical interactions between plants) is known to affect individual performance, community structure and plant invasions. Yet, a quantitative synthesis is lacking. Here, we performed a meta-analysis of 384 studies that measured allelopathic effects of one species (allelopathy plant) on another species or itself (test plant). Overall, allelopathy reduced plant performance by $25 \%$, but the variation in allelopathy was high. The type of method affected the allelopathic effect: compared to leachates, allelopathy was more negative when residues of allelopathy plants were applied, and less negative when soil conditioned by allelopathy plants was applied. The negative effects of allelopathy diminished with study duration, and increased with concentrations of leachates or residues. Although allelopathy was not significantly related to lifespan, life form or domestication of the interacting plants, it became more negative with increasing phylogenetic distance. Moreover, native plants suffered more from leachates of naturalised alien plants than from leachates of other native plants. Our synthesis reveals that allelopathy could contribute to success of alien plants. The negative relationship between phylogenetic distance and allelopathy indicates that allelopathy might contribute to coexistence of closely related species (i.e. convergence) or dominance of single species.
\end{abstract}

Keywords

Crop, interference competition, invasive species, life history, meta-analysis, phylogeny, soil microbes, succession.

\section{INTRODUCTION}

Allelopathy refers to either the inhibitory or stimulatory effect of one plant on another through the production of chemicals and their release into the environment (Molisch 1937; Rice 1984). The earliest written record of allelopathy can be traced back to $c .300 \mathrm{BC}$, when the Greek philosopher Theophrastus noticed that, chick pea plants 'exhaust' the soil and destroy weeds (Hort 1916). To understand the roles of allelopathy in agriculture, forestry and old-field succession, numerous studies have been conducted since 1970 (Rice 1984; Cheng \& Cheng 2015). In the late-1990s, research on allelopathy gained even more attention as some studies revealed allelopathy as a driving mechanism for the success of some invasive plants (Wardle et al. 1998; Callaway \& Aschehoug 2000; Hierro \& Callaway 2003). Despite the long-standing interest and the mounting number of studies on allelopathy, we still lack a quantitative synthesis to answer whether allelopathy generally inhibits or stimulates plants.

So far, inhibitory effects of allelopathy have been found in some studies (Mahall \& Callaway 1992), but no or stimulatory effects have been found in others (Bauer et al. 2012; Zhang et al. 2015). Therefore, besides testing the overall effect of allelopathy, identifying the sources of heterogeneity can

'Ecology, Department of Biology, University of Konstanz, Konstanz 78464, Germany

${ }^{2}$ Key Laboratory of Wetland Ecology and Environment, Northeast Institute of Academy Sciences, Changchun 130102, also improve our understanding (Lankau 2009; Tharayil et al. 2009; Meiners et al. 2012). The first candidate source is the method to study allelopathy. For example, to test allelopathy, some studies soaked seeds in leaf leachates or root exudate from other plants, and some grew seedlings on substrate mixed with residues from other plants (see Table 1 for a summary of the major methods that have been used to test allelopathy). The differences in study method partly reflect the four pathways through which allelochemicals are released into the environment, that is, leaching from plants by rain, decomposition of plant residues (e.g. litter), exudation from roots and volatilisation (Fig. 1; Rice 1984 p309). However, studies also differ with regard to the different life stages of plants (e.g. germination vs. growth) and the duration of the experiment. Disentangling the importance of the different factors related to the study design can hardly be achieved in a single case study, but is feasible in a quantitative synthesis, such as meta-analysis (Gurevitch et al. 2018).

Variance in allelopathy can also arise from biological traits of plants. Several studies of plant succession revealed that the effect of allelopathy may depend on life history. For example, Jackson and Willemsen (1976) reported that ragweed (Ambrosia artemisiifolia) and wild radish (Raphanus raphanistrum), which are short-lived, early successional species, cannot

\footnotetext{
${ }^{3}$ Zhejiang Provincial Key Laboratory of Plant Evolutionary Ecology and Conservation, Taizhou University, Taizhou 318000, China ${ }^{4}$ Department of Biodiversity Research, Institute of Biochemistry and Biology, University of Potsdam, Potsdam 14469, Germany

*Correspondence: E-mail: liuyanjie@iga.ac.cn
} 
Table 1 A description of the seven types of methods used to test for allelopathy. We also indicate which of the four pathways of allelopathy (see Fig. 1) the method tests

\begin{tabular}{lll}
\hline Method & $\begin{array}{l}\text { Description } \\
\text { Leachate }\end{array}$ & $\begin{array}{l}\text { Leachates were made by soaking plant } \\
\text { biomass (usually leaves) of the allelopathy } \\
\text { plant in water, or in a mixture of water and } \\
\text { an organic solvent, for a certain time } \\
\text { (ranging from a few hours to days). Then, } \\
\text { the leachate was applied to the test plants. }\end{array}$ \\
Biomass (litter or fresh biomass) of the \\
allelopathy plant was directly incorporated \\
into the substrate of the test plants.
\end{tabular}

*The abbreviations correspond to the pathways in Figure 1. P1: leachate; $\mathrm{P} 2$ : residue; $\mathrm{P}$ 3: exudate; $\mathrm{P} 4$ : volatile.

re-establish on soils on which the long-lived, late-successional frost aster (Aster pilosus) grew previously. Besides life history, domestication may also matter as crop species appear to be more sensitive to allelopathy than weeds (Sera 2012). From an evolutionary perspective, individuals of short-lived species are associated with other species for a shorter period than long-lived species are (Myster \& Pickett 1992). Likewise, crop species are less exposed to interference with other species (e.g. weeds) as they are frequently protected by humans. Consequently, the abilities to inhibit other species and to tolerate inhibition from others are less likely to be selected for in short-lived species or crops (Meiners et al. 2012). However, whether this is true remains untested at a broad scale.

The strength and direction of allelopathic interactions may also depend on two other aspects of evolutionary history: phylogenetic distance and species origin. On the one hand, the composition of secondary metabolites (i.e. allelochemicals) is generally phylogenetically conserved in plants (Wink 2003; Grutters et al. 2017). Therefore, distantly related species might strongly inhibit each other due to little overlap in, and thus novelty of, their allelochemical profiles. On the other hand, evolutionary history is also shaped by the conditions that a species has experienced. In their native range, alien plants interacted with other species (e.g. competitors and enemies) than they do in their non-native range (Liu \& Stiling 2006; Blumenthal et al. 2009; Saul \& Jeschke 2015). Therefore, the aliens might have evolved different arsenals of allelochemicals to which the natives, in the non-native range of the aliens, are not adapted. This is known as the Novel Weapons hypothesis (Callaway \& Ridenour 2004). For example, Callaway and Aschehoug (2000) found that the Eurasian Centaurea diffusa, a noxious invasive weed in North America, had more negative effects on species native to North America than on species native to Eurasia. The other way around, the natives may also produce arsenals of allelochemicals to which introduced aliens are not adapted, and this might provide biotic resistance (Rabotnov 1981; Cummings et al. 2012; Ning et al. 2016). Still, the importance of phylogenetic distance and novelty for the strength of allelopathic interactions and the consequences for invasion success of alien plants remain unknown.

Although there are still many open questions in allelopathy research, the past decade has witnessed a slowdown of research on allelopathy (Fig. S1). There are possibly two major reasons for this. First, retractions and corrections of several high-profile publications - whose findings could not be repeated by subsequent studies (Blair et al. 2005; Perry et al. 2007) or were identified as being fabricated (Borrell 2015; Palus 2016) - have haunted the field. Second, some of the techniques to study allelopathic effects have been questioned (e.g. Lau et al. 2008, Blair et al. 2009). Therefore, to assess the overall evidence for allelopathy and to quantify its effects, we conducted a meta-analysis. Importantly, we also identified sources of variance in allelopathy by testing whether allelopathy is related to study design (including the techniques used), biological traits of species and evolutionary history. Finally, to provide new avenues for future studies, we identified some of the knowledge gaps in present allelopathy research.

\section{METHODS}

\section{Literature search}

We searched ISI Web of Science for between-plant-allelopathy studies that were published between January 1900 and December 2017. We used the search string 'allelopath* AND plant', which resulted in 3699 papers. This list of papers was further expanded by including all papers that were published in the Allelopathy Journal (ISSN 0971-4693) between 1994 (the year that the journal was first published) and 2017, which resulted in another c. 900 papers. We then screened the titles, abstracts and main texts. Studies were included if the following criteria were met:

(1) The study tested a pairwise interaction, that is, the effect of one species on another or on conspecifics. Therefore, studies that tested effects of allelopathy on a community, that tested effect of mixed species and that tested effects of single allelochemicals on plants were excluded.

(2) The study tested allelopathy using one of the seven major methods listed in Table 1.

(3) The study measured traits related to germination, growth or fitness, and thus studies that measured other traits, 


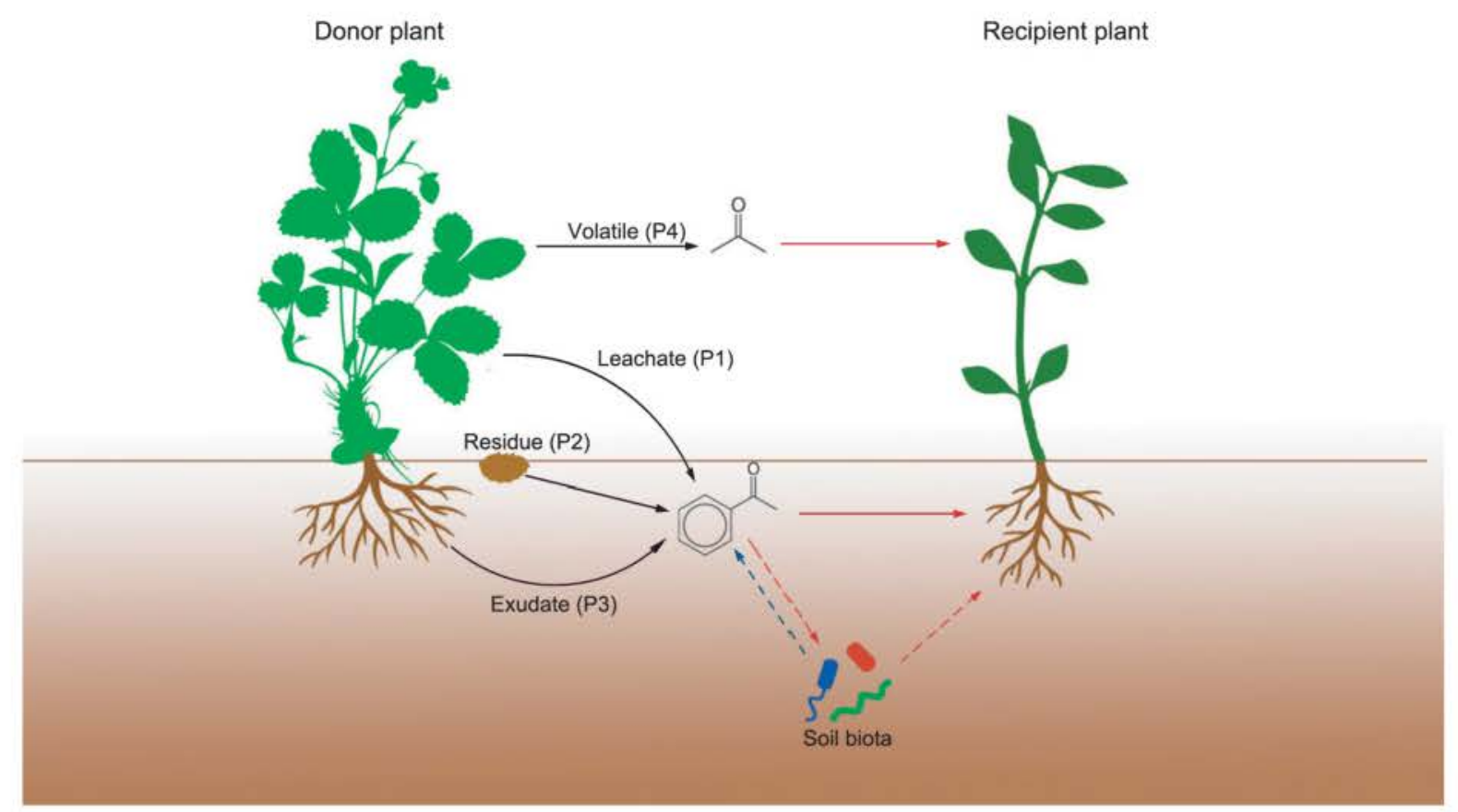

Figure 1 The different release pathways and effects of allelochemicals. The allelopathy plant (left) can release allelochemicals through four pathways (black arrows): leaching by rain ( $\mathrm{P} 1)$, decomposition of plant residues ( $\mathrm{P} 2)$, exudation from roots (P3) and volatilisation (P4). The allelochemicals can affect the test plant directly (red arrows) or indirectly through their effect on soil biota (dashed red arrows). Soil biota can also affect allelochemicals, such as through conversion or degradation of allelochemicals. The root illustration is designed by Brgf $\mathrm{x} / \mathrm{Freepik}$.

such as mycorrhizal colonisation and the concentration of chlorophyll, were excluded. Germination measurements include germination rate (i.e. proportion of seeds that germinated), germination speed and time to germination. Growth measurements include total biomass and biomass of different plant parts (shoots, roots, leaves and stem); lengths of roots and shoots; numbers of leaves and branches; leaf size; and stem diameter. Fitness measurements include biomass of seeds, fruit and flowers, and numbers of seeds, fruit, flowers and ramets.

(4) The study used seed plants (i.e. the few studies that used algae or ferns were excluded).

(5) The study reported the duration of the experiment.

(6) Mean values and variances (standard deviations, standard errors or $95 \%$ confidence intervals) of control and allelopathy treatments could be obtained from the text, tables, figures or supplements.

\section{Data collection}

In total, 378 published papers met our criteria. We also added data of six experiments from our laboratories, two of which were published after 2017 (Zhang et al. 2018; Oduor et al. 2020). So, we included 384 studies in total. If a study sampled data at multiple time points, we only extracted the final data points to avoid temporal autocorrelation. If a study tested multiple species pairs, applied multiple treatments (e.g. different concentrations of leachates), we considered them as independent observations. For each observation, we extracted the mean values, variances and sample sizes of the test species, under control and allelopathy treatments. Data from figures were extracted using ImageJ (Abràmoff et al. 2004). We recorded study duration, the plant part used for making the allelopathy treatment (shoot, root and whole plant), the concentration of leachates or residues if it was reported in the paper. Besides, we recorded the experimental environment, that is, controlled (Petri dishes, growth chamber or greenhouse), semi-natural (outdoor experiment that was not under natural conditions) or natural environment. Our final data set contained 16,810 data points covering 461 allelopathy species and 470 test species.

In addition to the data extracted from the papers, we acquired three biological traits - lifespan (short- or longlived), life form (woody or non-woody) and domestication (crop or wild) - of the species by matching their names with several databases. Before matching our database with others, we harmonised taxonomic names of all species according to The Plant List (http://www.theplantlist.org/), using the Taxonstand R package (Cayuela et al. 2017). 
We extracted the information on lifespan and life form from the following databases: TRY (Kattge et al. 2020; last accessed on 9 November 2015), the World Checklist of Selected Plant Families (WCSP; http://wcsp.science.kew.org/; last accessed on 22 August 2018), Plants for a Future (PFAF, https://pfaf.org/; last accessed on 22 August 2018), LEDA (Kleyer et al. 2008; last accessed on 22 August 2018) and PLANTS (http://plants.usda.gov/; last accessed on 22 August 2018). We classified annual and biennial species as short-lived, and perennials as long-lived. A few species were not included in the databases $(29 \%$ in case of lifespan and $16 \%$ in case of life form). For them, we extracted the information on lifespan and life form from the description of the species in the allelopathy papers or we did internet searches to find this information. We classified a species as a crop species in the narrow sense if it is recorded as a human food in the World Economic Plants (WEP) database (National Plant Germplasm System GRIN-GLOBAL; https://npgsweb.ars-grin.gov/grin global/taxon/taxonomysearcheco.aspx, last accessed on 7 January 2016), which is based on a book by Wiersema and León (2013). However, because crops are not restricted to plants grown for human food, we also used a broader classification in which a species was classified as a crop if it is recorded to have any economic use according to the WEP database. The results based on the broader definition of crop (Table S1) were very similar to those based on the narrower definition, indicating that the results on crop vs. non-crop species are robust.

We also acquired data on the origin of the species (i.e. native or alien at the location of study), and in the case of alien species, we distinguished between non-naturalised and naturalised species. The latter are species that have established self-perpetuating populations in the wild at the location of study (sensu Richardson et al. 2000). For this, we used three databases - the Global Naturalized Alien Flora (GloNAF), the Germplasm Resources Information Network (GRIN) and the Plants of the World Online portal (POWO). The GloNAF database contains lists with naturalisation status of 13,939 alien vascular plant taxa for 1,029 regions (countries or subnational administrative units; van Kleunen et al. 2019). GRIN is an online database published by the United States Department of Agriculture (USDA; https://www.ars-grin.gov/; last accessed on 2 March 2020). POWO is an online database published by the Royal Botanic Gardens, Kew (http://powo.scie nce.kew.org/; last accessed on 2 March 2020). All of them provide descriptions of the distribution of the taxa.

We classified a species at the location of study as a naturalised alien if GloNAF or GRIN reported that it is naturalised there; as native if GRIN, POWO or the study reported that it is native there; as non-naturalised alien if the species is recorded there neither as native nor as naturalised by any of the data sources. Five studies tested for allelopathic effects of an alien species collected in its non-native region on species that had been collected in the native region of the alien species (Callaway \& Aschehoug 2000; Prati \& Bossdorf 2004; Abhilasha et al. 2008; Gruntman et al. 2016; Oduor et al. 2020). As, in these cases, it is not clear whether the allelopathy and test species should be considered native or alien, we excluded such species pairs from analysis.
We constructed a phylogenetic tree for all species in our data set (Supplement S3) by pruning an existing phylogenetic supertree using the R function S.PhyloMaker (Qian \& Jin 2015). The supertree, which was initially constructed by Zanne et al. (2014) and further corrected and expanded by Qian and Jin (2015), included 30,771 seed plants, and has been time-calibrated for all branches using seven gene regions (i.e. 18S rDNA, 26S rDNA, ITS, $m a t K, r b c L$, atpB and $t r n L-F$ ) available in GenBank and fossil data. Species that were absent in the supertree (about $21.6 \%$ ) were added as polytomies to the root of their genus or family. We calculated the pairwise phylogenetic distance between allelopathy and test species using the cophenetic function in the ape package (Paradis \& Schliep 2018).

\section{Effect size calculation}

As effect size, we calculated the $\log$ response ratio $(\ln R R$; Borenstein et al. 2009) as:

$$
\ln R R=\ln \left(\bar{X}_{\text {allelopathy }}\right)-\ln \left(\bar{X}_{\text {control }}\right) .
$$

where $\bar{X}_{\text {allelopathy }}$ and $\bar{X}_{\text {control }}$ are the mean values of performance (germination, growth or fitness) of a test species in the allelopathy and control respectively. When a high value of a measured trait indicates low performance of plants (e.g. for a given species, a high value for germination time indicates low success of germination), we changed the sign of the effect sizes of this trait. Consequently, a negative value of $\ln R R$ indicates that allelopathy reduced plant performance, and a positive value indicates that allelopathy increased plant performance.

The sampling error variance of the $\ln R R$ was calculated as:

$$
v=\frac{S_{\text {allelopathy }}^{2}}{n_{\text {allelopathy }} \bar{X}_{\text {allelopathy }}^{2}}+\frac{S_{\text {control }}^{2}}{n_{\text {control }} \bar{X}_{\text {control }}^{2}}
$$

where $S$ and $n$ are the standard deviation and sample size respectively (Borenstein et al. 2009).

\section{Statistical analyses}

All analyses were carried out with Bayesian multivariate models implemented in the brms package (Burkner 2017) in R 3.6.1 (R Core Team 2019), which allowed us to account for phylogenetic non-independence of the species and to include both the sampling error and the residual error. We considered an estimated parameter as significant when its $95 \%$ credible interval of the posterior distribution did not overlap zero, and as marginally significant when the $90 \%$ credible interval did not overlap zero.

\section{Meta-analysis}

To test the overall effect of allelopathy, we ran an interceptonly meta-analysis model. We included effect size $(\ln R R)$ as response variable; and study identity (i.e. paper), species identity and phylogenetic effect (added as phylogenetic variancecovariance matrices) of allelopathy and test species as random effects. We specified standard errors of the observations (squared root of the variance) to weight the effect size by its precision. Note that both the species identity and phylogenetic 
effect of species are species-specific effects, but that the former represents the non-phylogenetic part (Nakagawa \& Santos 2012).

We used the default priors set by the brms package, but changing the priors had negligible effect on our results. We ran four independent chains with 3000 iterations each. Half of the iterations were used as warm-up, so a total of 6000 samples were retained to estimate the posterior distribution of each parameter. We quantified heterogeneity of the model by estimating $I^{2}$ sensu Nakagawa and Santos (2012) (see Supplement S4 for details). The phylogenetic signal was quantified by $H^{2}$, which is a metric of phylogenetic signal named phylogenetic heritability (Lynch 1991). Similar to the widely used metric of phylogenetic signal Pagel's $\lambda$ (Pagel 1999), $H^{2}=0$ indicates that there is no effect of phylogenetic relatedness of species on their difference in effect sizes, while $H^{2}=1$ indicates that the differences in effect sizes are exactly proportional to the phylogenetic relatedness of the species. To report the effect of allelopathy on plant performance at the raw-data scale, we back-transformed the $\log$ response ratio $(\ln R R)$ with the formula: $\mathrm{e}^{\ln R R}-1$. For example, $\ln R R=-0.5$ indicates that allelopathy reduced plant performance by $39.3 \%$ $\left(\mathrm{e}^{-0.5}-1\right)$.

\section{Meta-regressions}

To test the importance of different sources of variance in allelopathy, we ran three meta-regression models (i.e. mixedeffects meta-analyses). The first model included data from all seven methods described in Table 1 combined. The second and third models analysed two subsets, that is, the leachate and the residue method respectively. These two models allowed us to analyse certain aspects of the experimental design in more detail. For example, the concentration of the allelopathic agents was not manipulated in all seven methods (e.g. activated-carbon method), and thus cannot be tested in the first model. We also ran meta-regression models for each of the other five methods, but because the number of studies was relatively small, we report their results in the supplements (Supplement S5). In all models, we included effect size as response variable; and used the same random effects, priors, warm-up and sampling as in the intercept-only meta-analysis described in the 'Meta-analysis' subsection above.

In the first model, we included the following explanatory variables as fixed effects: (1) type of method (leachate, residue, activated carbon, solvent, soil, volatile and exudate; see Table 1); (2) type of performance measure (germination and growth; as only 10 studies measured fitness, we combined fitness with growth); (3) experimental environment (controlled, semi-natural and natural); (4) study duration (days); (5) lifespan (short-lived [annual and biennial] and long-lived [perennial]) of allelopathy and test species; (6) life form (herbaceous and woody) of allelopathy and test species; (7) domestication (crop and wild) of allelopathy and test species; (8) phylogenetic distance between allelopathy and test species; and (9) origin (native, naturalised alien and non-naturalised alien) of allelopathy and test species, and interaction between origin of allelopathy and test species.

Variables 1-4 are those related to the experimental design. Variables 5-7 are those related to biological traits. Variables 8 and 9 are those related to evolutionary history. Note, however, that the variables 5-7 (lifespan, life form and domestication) are also related to evolution. For example, crops were selected for high yield by humans. However, the variables 8 and 9 (phylogenetic distance and origin) focus on the similarity in evolutionary history between allelopathy and test species, for example, their relative positions on the phylogenetic tree.

In the second and third models, which focused on studies that used the leachate and residue methods, respectively, we included the same fixed effects as in the first model, except for type of method. Consequently, the models included the following fixed effects: (1) type of measurement; (2) experimental environment (not for leachate, because there was no semi-natural or natural experiment); (3) study duration; (4) lifespan of allelopathy and test species; (5) life form of allelopathy and test species; (6) domestication of allelopathy and test species; (7) phylogenetic distance between allelopathy and test species; and (8) origin of allelopathy and test species, and their interaction.

We included another three fixed effects related to the study design, which could not be included in the first meta-regression model: (9) 'colour' of biomass (fresh biomass [green] and litter [brown]); (10) plant part (belowground, aboveground part and whole plant); (11) concentration of leachates or residues.

Because the concentration of secondary metabolites, study duration and phylogenetic distance have been found or hypothesised to be nonlinear (Rice 1984; Reich et al. 2018; Malecore et al. 2019), we considered nonlinear effect for all of them. To do this, we first ran models that applied data transformation (natural-log and square-root transformation), included quadric terms or specified nonlinear curves (Monod equation and Weibull curve). Then, we performed model selection with the leave-one-out cross-validation method using the loo package (Vehtari et al. 2016). In the end, we natural$\log$ transformed study duration and concentration of leachates or residues and added quadric terms for those variables, while we used the original linear scale for phylogenetic distance. To improve comparability of the coefficient estimates, we bounded phylogenetic distance, which ranges from 0 (i.e. same species) to 781 million years, between 0 and 1 .

To improve interpretation of the intercept (Schielzeth 2010) and to aid comparisons between different meta-regression models, we mean-centred all categorical explanatory variables with two levels after coding them as dichotomous $(0$ and 1$)$ variables. For categorical variables with more than two levels, we set the most common levels as the reference levels. For type of method this was 'leachate', for experimental environment this was 'controlled', for plant part this was 'aboveground part' and for origin of allelopathy and test species this was 'native'. For all continuous variables, we applied mediancentering instead of mean-centering because their distributions were skewed.

For the concentration of leachates or residues, studies used three types of units (weight/weight, $\mathrm{g} / \mathrm{g}$; weight/volume, $\mathrm{g} / \mathrm{cm}^{3}$; and weight $/$ area, $\mathrm{g} / \mathrm{cm}^{2}$ ), which differ in their scales and might have different per-unit effects. To account for this, we included type of unit and set 'weight/weight', the most common level, as the reference level in the model for residue method. In the model for leachate method, all but two studies 
used the unit of weight/volume, and we therefore removed the two exceptions from the analysis. Finally, of the studies that used the residue method, only a few used non-naturalised alien species. For example, only two studies tested the effect of non-naturalised aliens on natives. Therefore, we did not discriminate between non-naturalised and naturalised aliens in the model for the residue method.

\section{Detection of publication bias}

Because statistically significant results are more likely to be published than non-significant results (Rosenthal 1979), publication bias can affect the results of meta-analyses. To test for publication bias, we first used the funnel plot method by plotting metaanalytic residuals against the inverse of their precision (i.e. inverse of the sampling error). When the funnel plot is asymmetric, one can conclude that publication bias is present. The metaanalytic residual is the sum of a within-study effect (analogy to residual in linear models) and a sampling error effect (Nakagawa \& Santos 2012), and was extracted from the meta-analysis (the intercept-only model). Second, we performed a modified Egger's regression (Egger et al. 1997; Nakagawa \& Santos 2012) by using the meta-analytic residuals as the response variable, and the precision as the explanatory variable. When the intercept does not overlap zero, one can conclude that publication bias is present. Finally, we analysed the temporal trends in effect sizes. A so-called time-lag bias arises when the earliest published studies have larger effects than those of later studies (Trikalinos \& Ioannidis 2005). To do so, we ran a meta-regression model that included effect size as response variable, and publication year as the only fixed effect.

\section{RESULTS}

Our meta-analysis showed that allelopathy was, overall, inhibitory, as it reduced plant performance by on average $25.3 \%$ (mean $\ln R R=-0.288,95 \%$ CI $=[-0.492,-0.052]$ ). As expected, the heterogeneity in effect size was high. Withinstudy heterogeneity (i.e. at the observation level) accounted for $53.6 \%$ of the variance, between-study heterogeneity accounted for $26.2 \%$ of the variance, between-test-species heterogeneity (i.e. the non-phylogenetic part) for $13.0 \%$ of the variance and between-allelopathy-species heterogeneity for $7.1 \%$ of the variance (Table S2). The phylogenetic signal was low, both among allelopathy species $\left(H^{2}<0.01 \%\right)$ and among test species $\left(H^{2}=0.02 \%\right.$; Table S2).

\section{Effects of study design on allelopathy}

The type of method significantly affected the effect of allelopathy (Fig. 2a; Table 2). Compared to the leachate method, the effect of allelopathy was more negative $(-15.1 \%)$ when the study used residues $\left(\ln R R_{\text {residue-leachate }}=-0.163\right.$ $[-0.220,-0.107])$, and less negative $(+13.0 \%)$ when the study used soil on which the allelopathy species was grown ( $\left.\ln R R_{\text {soil-leachate }}=0.122[0.024,0.218]\right)$. The effect of allelopathy in studies that used activated carbon, exudate, volatile or solvent extraction did not deviate significantly from those that used leachates.
Allelopathy had overall weaker negative effects $(+15.1 \%)$ on germination than on plant growth ( $\ln R R_{\text {germination-growth }}=$ $0.140[0.119,0.161]$; Fig. 2a; Table 2 ). This was particularly true when allelopathy was tested with leachates (Table S4). However, when tested with residues, allelopathy had stronger negative effects $(-25.7 \%)$ on germination than on plant growth ( $\ln R R_{\text {germination-growth }}=-0.297$ [ $\left.-0.387,-0.208\right]$; Table S5). Allelopathy had less negative effects $(+26.7 \%)$ in experiments done under semi-natural conditions than under controlled conditions ( $\ln R R_{\text {seminatural-controlled }}=0.237[0.058$, 0.411]; Fig. 2a; Table 2), whereas allelopathic effects did not significantly differ between experiments done under natural and controlled conditions. We also found that leachates from belowground parts of plants had weaker negative effects $(+13.6 \%)$ than leachates from aboveground parts $\left(\ln R R_{\text {below-above }}=0.127\right.$ [0.095, 0.160]; Table S4).

The effects of study duration and concentration of leachates or residues on allelopathy were weakly non-monotonic, as indicated by the significant quadric terms (Fig. 2b and c; Table 2). Allelopathic effect was negative for experiments of short duration, but was not significantly different from zero when the experiments lasted over 89 days. The effect of low concentrations of leachates or residues was not significantly different from zero, but became significantly negative when the concentration of leachates (or residues) exceeded $0.055 \mathrm{~g} /$ $\mathrm{ml}$.

\section{Effects of biological traits on allelopathy}

Overall, allelopathy did not differ between short- and longlived species, between herbaceous and woody species, and between crop and wild species (Fig. 3; Table 2). This holds for both the allelopathy and test species (Fig. 3; Table 2).

\section{Effects of evolutionary history on allelopathy}

The effect of allelopathy became slightly more negative as the phylogenetic distance between allelopathy and test species increased (Fig. 4a; Table 2). More specifically, the effect of allelopathy between the most closely related species (or individuals of the same species) reduced plant performance of each other by $28.2 \%(\ln R R=-0.331,[-0.521,-0.119])$, whereas that between the most distantly related species reduced plant performance by $41.0 \% \quad(\ln R R=-0.528$, $[-0.731,-0.319])$. Across all seven methods (Table 1), allelopathy was not affected by the origin of the allelopathy and test species, or by the interaction between the origins of the two species (Table 2). However, for the subset of studies that tested the effect of leachates, we found that natives experienced more negative $(-13.4 \%)$ effects from naturalised alien species than from other natives ( $\ln R R_{\text {naturalizedonnative-nativeonnative }}=-0.143 \quad\left[\begin{array}{lll}-0.286, & -0.004\end{array}\right]$; Fig. 4b; Table S4). In addition, allelopathic effects between two naturalised aliens tended to be less negative $(+13.2 \%)$ than allelopathic effects between two natives (In $R R_{\text {naturalizedonnaturalized nativeonnative }}=0.124 \quad[-0.011,0.260]$; Fig. 4b; Table S4), although this was only marginally significant. 

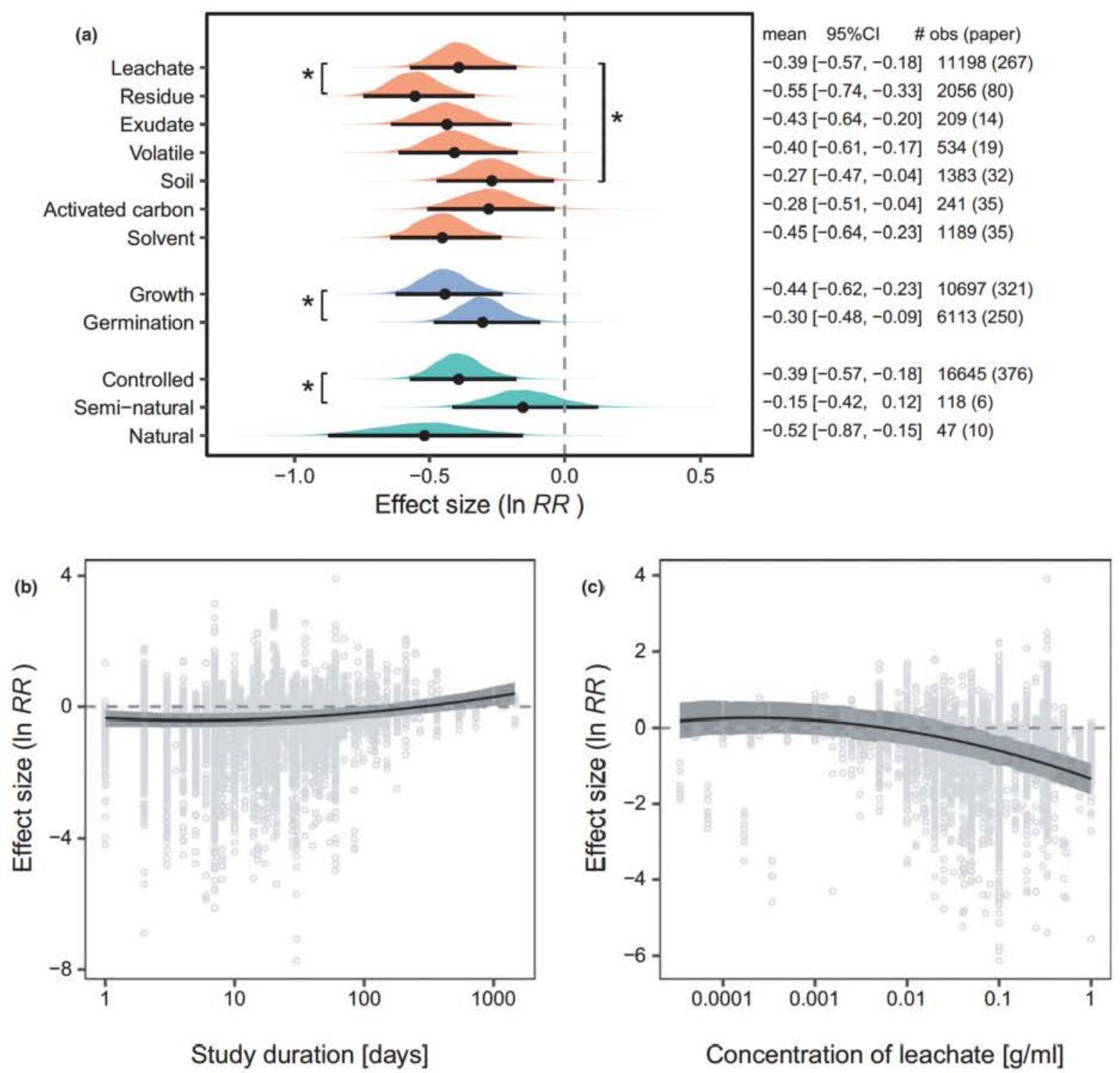

Figure 2 Effects of different aspects of study design on allelopathy. (a) Effects of the type of method (orange), the type of performance measure (blue) and the experimental environment (green) on allelopathy. (b) Effect of study duration on allelopathy. (c) Effect of the concentration of leachates on allelopathy. In (a) for each category (parameter), the posterior distribution is plotted with the mean and $95 \%$ credible interval. The text on the right displays the mean, $95 \%$ credible interval (CI), and the number of observations (obs) and papers. An asterisk indicates a significant difference between the level of interest and the reference level. In (b) and (c), curves of the estimated effects are shown with their $95 \%$ credible intervals. Negative values of the effect size (ln $R R$ ) indicate that allelopathy inhibits plant performance.

\section{Publication bias}

The funnel plot of the meta-analysis residuals is asymmetric (Fig. 5a), suggesting some publication bias in the literature. In particular low-precision studies are more likely to report strong negative than strong positive effects, suggesting that the latter are less likely to be published. The presence of a publication bias is confirmed by Egger's regression, as the intercept differed significantly from zero (Intercept $=-1.485$ $[-1.704,-1.266])$. However, we did not find a significant relationship between effect size and year of publication (Fig. 5b).

\section{DISCUSSION}

Overall, allelopathy reduced plant performance by $25 \%$. By comparison, competition - which might also include allelopathic effect - reduces plant performance by $43 \%$ (Lekberg et al. 2018), and herbivores consume $5 \%$ of leaf tissues produced annually by plants (Turcotte et al. 2014). Therefore, allelopathy can be a 
Table 2 Output of the model testing effects of study design, biological traits and evolutionary history on effect sizes (ln $R R$ ) of allelopathy. Shown are the model estimates and standard errors as well as the lower $(\mathrm{L})$ and upper $(\mathrm{U})$ values of the $95 \%$ and $90 \%$ credible intervals $(\mathrm{CI})$

\begin{tabular}{|c|c|c|c|c|c|c|c|}
\hline & & Estimate & SE & $\mathrm{L} 95 \% \mathrm{Cl}$ & U95\% CI & $\mathrm{L} 90 \% \mathrm{CI}$ & U90\% CI \\
\hline & Intercept (Leachate) & $-0.388^{*}$ & 0.099 & -0.573 & -0.179 & -0.541 & -0.220 \\
\hline \multirow{11}{*}{ Study design } & Residue & $-0.163^{*}$ & 0.029 & -0.220 & -0.107 & -0.210 & -0.115 \\
\hline & Exudate & -0.043 & 0.053 & -0.145 & 0.061 & -0.130 & 0.044 \\
\hline & Volatile & -0.015 & 0.050 & -0.114 & 0.082 & -0.098 & 0.067 \\
\hline & Soil & $0.122^{*}$ & 0.049 & 0.024 & 0.218 & 0.040 & 0.203 \\
\hline & Activated carbon & 0.109 & 0.071 & -0.029 & 0.247 & -0.007 & 0.227 \\
\hline & Organic solvent & $-0.061 \div$ & 0.032 & -0.124 & 0.001 & -0.113 & -0.009 \\
\hline & Measurement & $0.140^{*}$ & 0.011 & 0.119 & 0.161 & 0.123 & 0.158 \\
\hline & Experimental environment - semi-natural & $0.237^{*}$ & 0.090 & 0.058 & 0.411 & 0.089 & 0.381 \\
\hline & Experimental environment - natural & -0.132 & 0.152 & -0.432 & 0.168 & -0.379 & 0.120 \\
\hline & Study duration & $0.041^{*}$ & 0.016 & 0.009 & 0.072 & 0.014 & 0.068 \\
\hline & Study duration 2 & $0.025^{*}$ & 0.008 & 0.009 & 0.040 & 0.012 & 0.038 \\
\hline \multirow[t]{6}{*}{ Biological traits } & Lifespan (allelo) $^{\mathrm{a}}$ & 0.014 & 0.044 & -0.072 & 0.099 & -0.058 & 0.086 \\
\hline & Life form (allelo) & 0.046 & 0.039 & -0.030 & 0.125 & -0.019 & 0.112 \\
\hline & Domestication (allelo) & 0.031 & 0.041 & -0.047 & 0.112 & -0.036 & 0.097 \\
\hline & Lifespan (test) & 0.039 & 0.041 & -0.041 & 0.120 & -0.029 & 0.107 \\
\hline & Life form (test) ${ }^{b}$ & 0.049 & 0.056 & -0.060 & 0.158 & -0.042 & 0.140 \\
\hline & Domestication (test) & 0.053 & 0.044 & -0.033 & 0.141 & -0.018 & 0.126 \\
\hline \multirow[t]{9}{*}{ Evolutionary history } & Phylogenetic distance & $-0.195^{*}$ & 0.060 & -0.310 & -0.079 & -0.291 & -0.096 \\
\hline & Origin - naturalised (allelo) [O-N (allelo)] & -0.037 & 0.038 & -0.110 & 0.038 & -0.098 & 0.026 \\
\hline & Origin - non-naturalised (allelo) [O-NN (allelo)] & -0.017 & 0.058 & -0.128 & 0.095 & -0.111 & 0.079 \\
\hline & Origin - naturalised (test) [O-N (test)] & 0.051 & 0.039 & -0.026 & 0.127 & -0.012 & 0.117 \\
\hline & Origin - non-naturalised (test) [O-NN (test)] & 0.013 & 0.037 & -0.058 & 0.084 & -0.046 & 0.073 \\
\hline & $\mathrm{O}-\mathrm{N}$ (allelo)* O-N (test) & 0.019 & 0.049 & -0.080 & 0.114 & -0.064 & 0.099 \\
\hline & $\mathrm{O}-\mathrm{N}$ (allelo)* O-NN (test) & 0.054 & 0.046 & -0.036 & 0.143 & -0.022 & 0.129 \\
\hline & $\mathrm{O}-\mathrm{NN}$ (allelo)* O-N (test) & -0.040 & 0.068 & -0.174 & 0.091 & -0.150 & 0.071 \\
\hline & $\mathrm{O}-\mathrm{NN}$ (allelo)* O-NN (test) & -0.009 & 0.066 & -0.142 & 0.115 & -0.118 & 0.097 \\
\hline
\end{tabular}

Parameters whose $95 \%$ credible intervals do not overlap with zero are indicted with asterisks $\left({ }^{*}\right)$, and whose $90 \%$ credible intervals do not overlap with zero are indicated with daggers $(\dagger)$.

${ }^{a}$ Biological traits or origin of allelopathy species.

${ }^{\mathrm{b}}$ Biological traits or origin of test species.

significant force affecting the germination and growth of plants, and consequently the population dynamics of species and community assembly. However, the variation in magnitude and direction of allelopathy is high. Allelopathy was more negative when tested with plant residues than with leachates, and was less negative when tested with soil. Furthermore, the negative effect of allelopathy, generally, became weaker with study duration, and increasingly stronger with the concentrations of leachates and residues. Allelopathy was not significantly related to lifespan, life form and domestication of the two plant species. However, allelopathy became slightly but significantly more negative when phylogenetic distance between allelopathy and test species increased. In addition, native plants suffered more from leachates of naturalised alien plants than from leachates of other native plants, and effects of naturalised alien plants on each other were weak.

\section{Effects of study design on allelopathy}

Allelochemicals can be released into the environment by leaching from plants by rain, decomposition of plant residues, exudation from roots and volatilisation (Fig. 1). Our meta-analysis revealed that the effects of exudates and volatiles did not differ from those of leachates, but that plant residues had the most negative effect on plant performance. As the leachates are usually made by soaking plant material in water for $c .1$ day, smaller amounts of chemicals might be released than from residues. The leachates treatment is nevertheless not unrealistic, because in nature leaching may only happen during periods of rain. Moreover, while leachates contain only water-soluble chemicals, residues could additionally release non-water soluble secondary metabolites, which increases the likelihood that some of those are toxic to test plants. In support of this idea, studies that extracted different fractions of plant secondary metabolites showed that fat-soluble chemicals exerted stronger negative effects than water-soluble ones (Table S10).

Studies that used soils on which allelopathy plants were grown had weaker negative effects than those that used leachates. The reasons are various. First, the two types of methods differed in the substrates. While about $90 \%$ of the soilmethod studies used natural soil, most leachate-method studies used artificial substrates. The abiotic characteristics of natural soil, such as higher bulk density, may hinder diffusion of allelochemicals (Parepa \& Bossdorf 2016). Second, the effect of natural soil might also arise from the presence or higher abundance of soil microbes (Mishra et al. 2013). A recent study found that a bacterial species (Arthrobacter sp. ZS) isolated from soil increased the degradation of allelochemicals produced by Ageratina adenophora (Li et al. 2017), suggesting that soil microbes can neutralise allelopathic effect. Third, few if any soil-method studies have ruled out the effect of the allelopathy plant on soil microbes through primary 


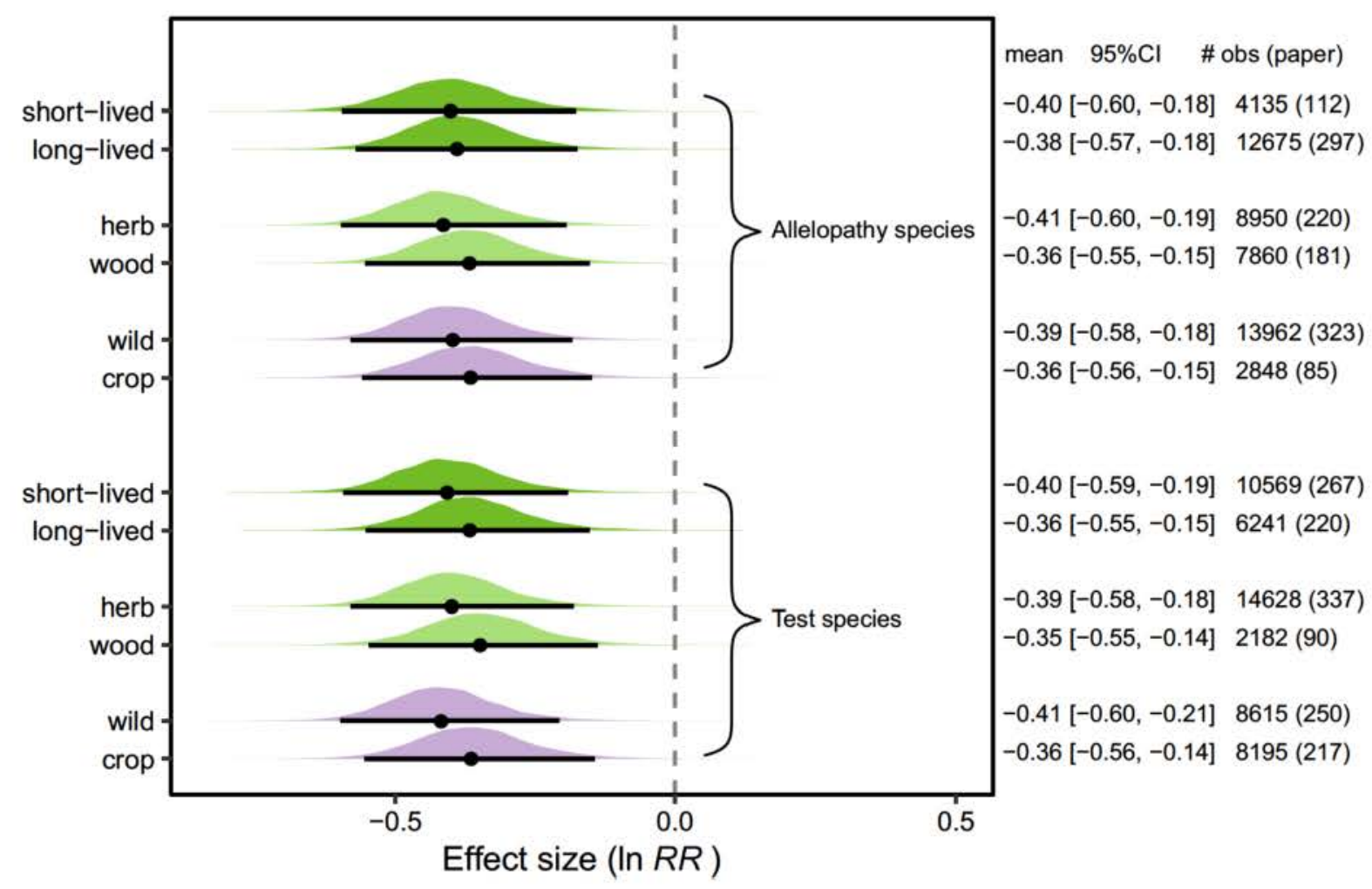

Figure 3 Effects of biological traits (lifespan, dark green; life form, light green; domestication, violet) on allelopathy. Biological traits of allelopathy species are shown in the upper half, and those of test species in the lower half. For each category (parameter), the posterior distribution is plotted with the mean and $95 \%$ credible interval. The text on the right displays the mean, $95 \%$ credible interval (CI), and the number of observations (obs) and papers. Negative values of the effect size $(\ln R R)$ indicate that allelopathy inhibits plant performance. No significant difference was found.

metabolites (e.g. plants can foster arbuscular mycorrhizal fungi), which are not involved in allelopathy but could neutralise allelopathic effect. So, future research needs to account for effects of soil that are not due to allelopathy.

The use of activated carbon in allelopathy studies is appealing, because it is easy to apply, and because it would allow to mimic natural conditions more closely (e.g. can be tested with resource competition). We found that allelopathic effects did not differ between studies that used activated carbon and those that used leachates. This suggests that the allelopathic effect is significant in the presence of resource competition. An important caveat, however, is that activated carbon can result in artefacts, such as increased nutrient availability (Lau et al. 2008). To account for artefacts, two questions need to be addressed: (1) whether and to which extent are the plants affected by activated carbon when grown in the absence of competitors? (2) whether and to which extent are the effect of resource competition affected by activated carbon? The latter is hard to test, but could be examined by fertilising plants that are competing (assuming that activated carbon indeed increases nutrient availability). However, such studies are still challenging because allelopathy and resource competition could interact. Consequently, as suggested by Lau et al. (2008), using other methods in addition to the activatedcarbon method will provide more compelling evidence.
Across the different types of methods, seed germination was less inhibited by allelopathy than plant growth was. This finding is not surprising given that seed germination is mainly determined by seed viability and abiotic environmental conditions, including temperature, water and oxygen concentrations (Bonnewell et al. 1983), which are unlikely to be affected by the allelopathy treatments. In contrast to the overall pattern, studies that tested allelopathy with plant residues showed that growth was less negatively affected than seed germination. As we also found that plants were less inhibited by litter than by fresh biomass, one potential explanation could be that plant residues (especially litter) increase nutrient availability, which partly offsets the inhibition of plant growth by allelochemicals. Still, the effect of allelopathy on fitness remains unclear as fitness was rarely measured.

The negative effect of allelopathy diminished with increasing duration of the experiment, and was absent in most studies that lasted over 89 days. Possibly, plastic responses of the test plants allow them to compensate for the early negative effects. This could suggest that allelopathy has no long-term impacts. However, if the plants also physically interact, like in nature, the allelopathy species could turn the short-term germination and growth inhibition of its competitors - which gives the allelopathic species more access to resources such as light - into a long-term competitive advantage (e.g. a priority effect; Fukami 

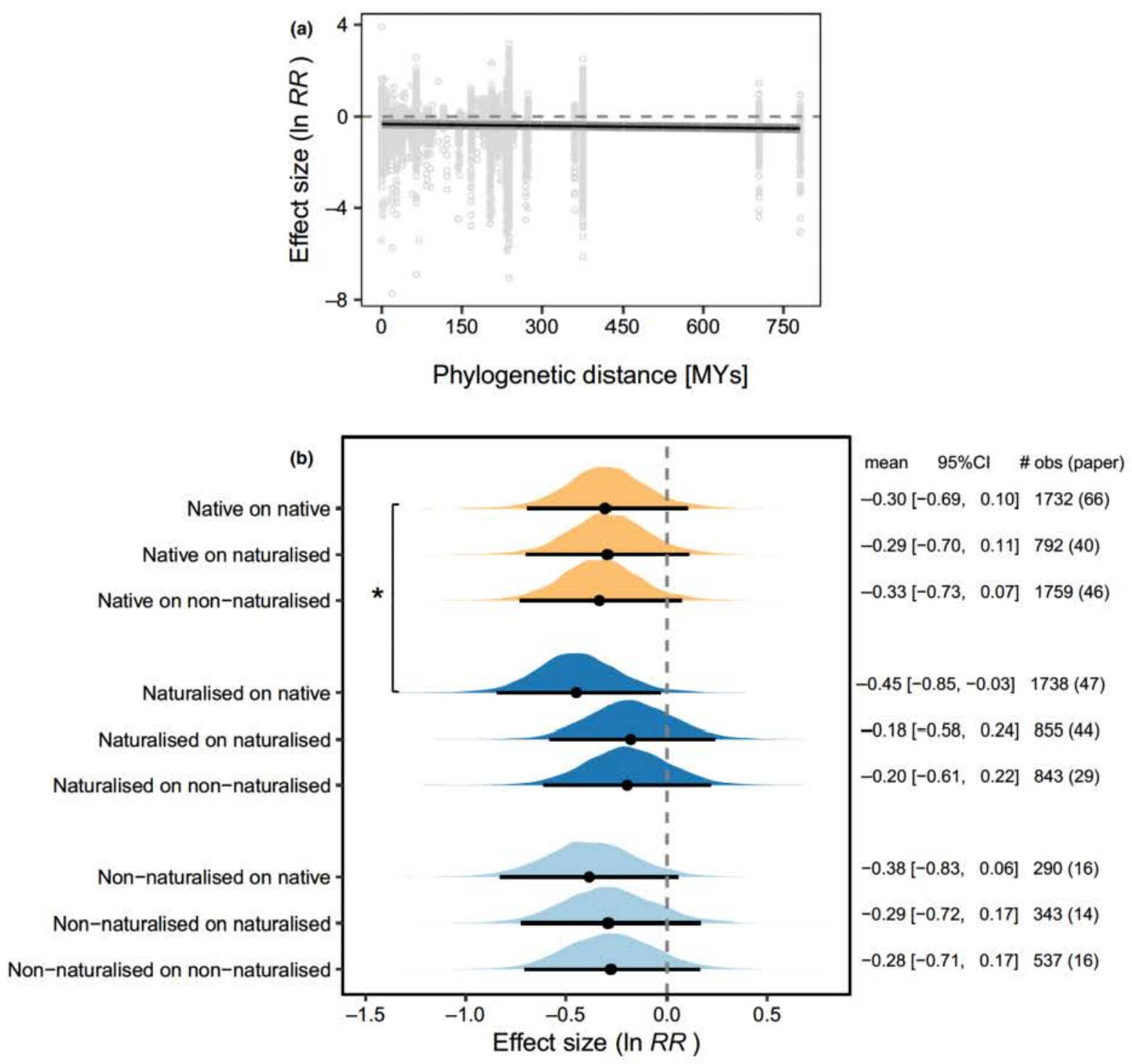

Figure 4 Effects of evolutionary history on allelopathy. (a) Effect of phylogenetic distance between allelopathy and test species on allelopathy. The curve of the estimated effect is shown with its $95 \%$ credible interval. (b) Effects of origin of allelopathy and test species on allelopathy when tested with the leachate method. Effects of native, non-naturalised alien and naturalised alien allelopathy species are shown in dark blue, light blue and orange. For each category (parameter), the posterior distribution is plotted with the mean and $95 \%$ credible interval. The text on the right displays the mean, $95 \%$ credible interval (CI), and the number of observations (obs) and papers. Negative values of the effect size ( $\ln R R$ ) indicate that allelopathy inhibits plant performance. An asterisk indicates significant difference between reference level (native on native) and the other.

et al. 2005). As long-term experiments are still rare and allelopathy is rarely tested in combination with other forms of competi= tion (e.g. resource competition, but see the activated-carbon method), this speculation requires further research.

As expected, the inhibitory effect of allelopathy became stronger with increasing concentrations of leachates and residues. An important question then is whether the concentration chosen is realistic. The few studies that give some clues show that the annual amount of plant litter varies largely among study sites, ranging from 43 to $884 \mathrm{~g} / \mathrm{m}^{2}$ (Facelli \& Carson 1991; San Emeterio et al. 2004; Chave et al. 2010; Overholt et al. 2012; Aguilera et al. 2015). Based on this range of concentrations, our model predicts that allelopathy through plant residues will reduce plant performance by $2.9 \%$ to $31.1 \%$, if we assume that the litter ends up in the upper $10 \mathrm{~cm}$ of soil that has a bulk density of $1.5 \mathrm{~g} / \mathrm{cm}^{3}$ (Martín et al. 2017). By comparison, our analysis of the residue method showed that allelopathy reduced plant performance by $50 \%$ across concentrations (intercept in Table S5). Consequently, the inhibitory effect of allelopathy might be overestimated by some studies that have used unrealistically high concentrations. A more realistic understanding of allelopathic effect requires (1) identifying putative 

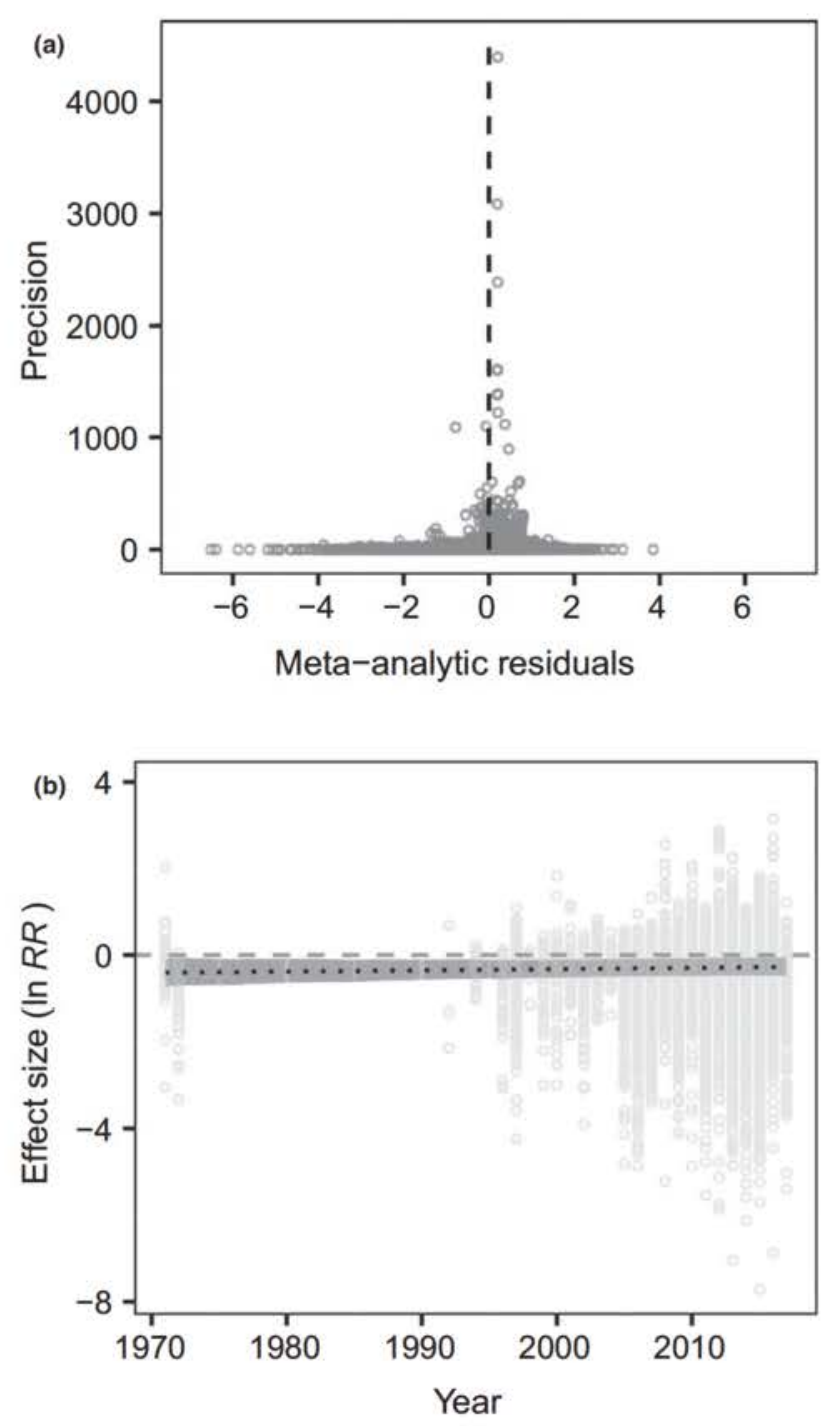

Figure 5 Tests of publication bias for the allelopathy studies used in our meta-analysis. (a) Funnel plot of the study precision (inverse of standard error) vs. the residuals of the meta-analysis. The asymmetry at low levels of precision indicates the presence of a publication of bias. The dashed line was added as visual reference for symmetry. A few data points with extremely high precision are not plotted to aid visualisation and a complete plot is provided in the supplement (Fig. S3). (b) The effect size $v s$. the year of study revealed no significant relationship.

allelochemicals, (2) measuring their corresponding concentrations in natural soil and (3) testing effects of allelochemicals at realistic concentrations.

\section{Effects of biological traits on allelopathy}

Allelopathy was not related to lifespan, life form or domestication of the species. This was unexpected, because many textbook examples of allelopathy are from long-lived trees, such as Juglans nigra (black walnut; Jose \& Gillespie 1998) and Ailanthus altissima (tree-of-heaven; Heisey 1990). Moreover, farmers have long been annoyed by weed interference on crop yield. The reported strong negative effects of some long-lived woody species in nature might come from the accumulation of large amounts of allelochemicals over time, whereas shortlived weedy species leave fewer allelochemicals due to their short generation time and high spatial turnover. When differences in strength of allelopathy between species with different life histories are only due to differences in accumulation of allelochemicals, and not due to differences in toxicity, these differences will not be apparent in short-term experiments with standardised amounts of plant material. On the other hand, the sometimes reported vulnerability of crops might be a result of the crops being grown in monoculture, resulting in a low diversity of allelochemicals, and consequently a lower resistance against invasion by weeds.

\section{Effects of evolutionary history on allelopathy}

Charles Darwin suggested that closely related species are more ecologically similar, and thus will compete more strongly with each other than when they compete with distantly related species (known as Darwin's naturalisation hypothesis; Darwin 1859). With regard to allelopathy, we found the opposite pattern, that is, that closely related species (or individuals of the same species) had weaker effects on each other than distantly related species. Our finding does not challenge Darwin's naturalisation hypothesis, because that hypothesis is mainly based on resource competition, whereas allelopathy is a form of interference competition. However, the possibly opposing effects of phylogenetic distance on interference and resource competition could help explain why studies testing Darwin's naturalisation hypothesis have not found consistent results (Thuiller et al. 2010).

Still, ecological differences between species, or more specifically the difference in secondary metabolites, cannot be fully captured by phylogenetic distance (Pichersky \& Lewinsohn 2011; Huang et al. 2016; Cadotte et al. 2017). Secondary metabolites are under selection by competitors and enemies (Uesugi \& Kessler 2013; Zheng et al. 2015), and thus plants that evolved in different regions (e.g. native and alien plants) may not be adapted to each other's allelochemicals. This might give the alien plants an advantage, as posed by the novel weapons hypothesis (Callaway \& Ridenour 2004), or increase biotic resistance of native communities, as posed by the homeland security hypothesis (Cummings et al. 2012; Ning et al. 2016). Although, across all types of methods, we did not find that the origins of the interacting species mattered, in the studies that used leachates, natives were more strongly inhibited by naturalised aliens than by other natives. On the other hand, the effect of natives on others did not depend on the native-alien status of the other species. So, these findings support the novelweapons hypothesis but not the homeland-security hypothesis.

Surprisingly, although naturalised aliens usually do not share a co-evolutionary history with other naturalised aliens (unless they have the same native range), their leachates had weaker effects on each other than was the case for the effects of natives on other natives (Fig. 4b). The exact reason for this is not clear, but it could imply that naturalised species are less likely to suppress other naturalised species than that they 
suppress natives. This could contribute to invasional meltdown (Simberloff \& Von Holle 1999).

\section{Future directions}

Our meta-analysis of 16,810 effects sizes from 384 studies revealed some clear patterns, but also that there is still lots of unexplained variation in the effects of allelopathy. The explanatory variables regarding study design, and biological traits and evolutionary history of the species accounted for only $3.5 \%$ of the variance, and $26.2 \%, 13.0 \%$ and $7.1 \%$ of the variance was explained by identities of study, test and allelopathy species respectively. This means that about $50 \%$ of the variance remains unexplained. Although this partly reveals the prevalence of heterogeneity in ecology and evolution in general, it also indicates that some other potential explanatory factors were not included. Below we suggest several directions that might help to better understand allelopathic effects.

\section{Positive effects of allelopathy}

Molisch (1937) defined allelopathy as the positive or negative effects resulting from biochemical interactions. However, Rice (1974), in the first edition of his influential book 'Allelopathy', restricted the definition to negative effects. Although in the second edition, Rice re-embraced Molisch's definition, the narrow-sense definition of allelopathy may explain the publication bias in favour of studies that found negative effects. As a result, some of our findings might be biased. For example, if studies that used low concentrations of allelochemicals found positive effects, they might not have published this result or the publication might not use the term 'allelopathy'. Actually, in the field of agriculture and horticulture, there is already interest in plant extracts (so-called biostimulants or bioeffectors) that could stimulate crop production (Wise et al. 2020). Due to the bias in publication of positive effects, nonmonotonic effect of concentration, if present, might be hard to detect using meta-analysis. Therefore, to move towards a more accurate understanding of allelopathy, we should follow Molisch's original definition of allelopathy, which covers both positive and negative effects.

\section{Soil microbes}

Soil microbes have long been acknowledged to mediate allelopathy (Fig. 1; Molisch 1937; Rice 1984; Cheng \& Cheng 2015). For example, Stinson et al. (2006) showed that allelochemicals of the non-mycorrhizal European invader Alliaria petiolata suppressed growth of native North American plants by disrupting their mutualistic mycorrhizal associations. Microbes might, however, also be a missing link in studies that test allelopathy between alien and native species. Specifically, as most experiments are ex situ, without adding native soil microbes to mimic the natural condition, the environment will be novel to both alien and native species. Consequently, the origin (alien vs. native) will be less relevant. Yet, empirical tests of how soil microbes affect allelopathy between plants remain rare. Four out of five direct tests found that the presence of soil microbes neutralised allelopathic effects (Wu et al.
2008; Lankau 2009; Zhu et al. 2011; Corbett \& Morrison 2012; Del Fabbro \& Prati 2015). However, caution must be taken, because three of the tests removed soil microbes with autoclaving, which as a side effect can release nutrients (Alphei \& Scheu 1993). Inoculation with soil microbes might be more appropriate to manipulate the presence or amount of microbes. In addition, with sequencing techniques becoming more and more affordable, we now have the tools to study the soil microbiome and its role in allelopathy in more detail.

\section{Test species}

Much of the work on allelopathy has focused primarily on the allelopathy species, as indicated by the fact that fast-growing crops (e.g. lettuce, wheat and rice) have been frequently used as test (indicator) species. We found, however, that the species identity of the test plant explained nearly twice as much variance in the allelopathic effect as the species identity of the allelopathy plant did $(13.0 \%$ vs. $7.1 \%)$. Therefore, although testing crops is valuable to agriculture, using certain fast-growing crops as indicators, just for convenience, could bias the estimation of allelopathic effect. A stronger focus on the test species may provide new insights. Indeed, how test species respond to allelopathy is important in many circumstances, such as during succession and establishment of alien plants. If a species enters a certain community as a single individual, its establishment will initially, due to its low abundance, hardly depend on how strongly it can affect other species. What matters then is how the individual responds to the communities (e.g. allelopathic effects of the resident plants on the invader). This is a key component of invasion growth rate (i.e. growth rate when rare; Grainger et al. 2019).

\section{The ecological and evolutionary significance of allelopathy}

Although we found that allelopathy was on average negative in experiments done under controlled conditions (i.e. in Petri dishes, growth chambers or greenhouses), it was non-significant in experiments under semi-natural conditions (i.e. in outdoor gardens or agriculture systems), where there were more organisms, interactions and environmental stochasticity. This conclusion is still premature, because we found a negative effect of allelopathy in experiments done under natural conditions, though with a wide $95 \%$ confidence interval; and because experiments under semi-natural or natural conditions are rare (e.g. 16 studies in our meta-analysis). Therefore, more experiments under natural conditions are needed to understand the ecological significance of allelopathy. In addition, secondary metabolites have functions other than allelopathy, such as anti-herbivory defence (Lankau \& Kliebenstein 2009). To understand the evolutionary significance of allelopathy, we require tests of whether the allelopathic effect is selected by competition per se or is a pleiotropic effect of secondary metabolites that are selected by herbivory.

\section{Uses of multiple literature search engines}

For our meta-analysis, we searched the ISI Web of Science for allelopathy studies. However, other search engines may 
identify additional studies. Indeed, a search a posteriori using the same search string as we used in Web of Science revealed that Scopus could potentially provide more studies (Supplement S6). Therefore, although our meta-analysis includes already a large number of studies (384) across the globe, broader searches (e.g. by combining ISI Web of Science, Scopus and China National Knowledge Infrastructure) could allow more general conclusions (Yu et al. 2016), and should be considered for future meta-analyses.

\section{CONCLUSIONS}

Studies on allelopathy have rapidly accumulated since the 1970s. Despite the detection of a potential publication bias, our global synthesis demonstrates that, on average, allelopathy reduced plant performance. Among the four pathways through which allelochemicals are released into the environment, plant residues exerted the most negative effect. Still, the importance of allelopathy in nature requires further investigation, as allelopathic effects were weaker in studies where soil microbes were likely to be abundant, and when study duration was longer. Finally, we found that allelopathic effects were weaker between closely related species (or individuals of the same species) than between distantly related species. This suggests that allelopathy would favour the coexistence of closely related species (or dominance of single species), which is opposite to the predicted effect of resource competition. Therefore, investigating allelopathy and resource competition jointly may explain the mixed outcomes of species coexistence.

\section{ACKNOWLEDGEMENTS}

We thank V. Pasqualetto for helping with data extraction; R. Hoefer, J. Kern, O. Michels, A. Oduor and D. Prati for sharing their data; and R. Hufbauer, ESA. Santos, the editor and one anonymous referee for helpful comments. ZZ acknowledges funding from the China Scholarship Council (201606100049) and support from the International Max Planck Research School for Organismal Biology. YL acknowledges funding from Chinese Academy of Sciences (Y9H1011001, Y9B7041001).

\section{AUTHORSHIP}

MvK and EW conceived the idea. ZZ, YL and MvK designed the study. ZZ, YL and LY collected the data. ZZ led the analyses and writing, with inputs from all others.

\section{REFERENCES}

Abhilasha, D., Quintana, N., Vivanco, J. \& Joshi, J. (2008). Do allelopathic compounds in invasive Solidago canadensis s.l. restrain the native European flora? J. Ecol., 96, 993-1001.

Abràmoff, M.D., Magalhães, P.J. \& Ram, S.J. (2004). Image processing with ImageJ. Biophotonics Int., 11, 36-42.

Aguilera, N., Becerra, J., Guedes, L.M., Villasenor-Parada, C., Gonzalez, L. \& Hernandez, V. (2015). Allelopathic effect of the invasive Acacia dealbata Link (Fabaceae) on two native plant species in south-central Chile. Gayana Bot., 72, 231-239.

Alphei, J. \& Scheu, S. (1993). Effects of biocidal treatments on biological and nutritional properties of a mull-structured woodland soil. Geoderma, 56, 435-448.

Bauer, J.T., Shannon, S.M., Stoops, R.E. \& Reynolds, H.L. (2012), Context dependency of the allelopathic effects of Lonicera maackii on seed germination. Plant Ecol., 213, 1907-1916.

Blair, A.C., Hanson, B.D., Brunk, G.R., Marrs, R.A., Westra, P., Nissen, S.J., et al. (2005). New techniques and findings in the study of a candidate allelochemical implicated in invasion success. Ecology Letters, 8, 1039-1047.

Blair, A.C., Weston, L.A., Nissen, S.J., Brunk, G.R. \& Hufbauer, R.A. (2009). The importance of analytical techniques in allelopathy studies with the reported allelochemical catechin as an example. Biol. Invasions, $11,325-332$.

Blumenthal, D., Mitchell, C.E., Pyšek, P. \& Jarošik, V. (2009). Synergy between pathogen release and resource availability in plant invasion. Proc. Natl Acad. Sci., 106, 7899-7904.

Bonnewell, V., Koukkari, W.L. \& Pratt, D.C. (1983). Light, oxygen, and temperature requirements for Typha-Latifolia seed-germination. Canad. J. Botany-Revue Canadienne De Botanique, 61, 1330-1336.

Borenstein, M., Hedges, L.V., Higgins, J.P.T. \& Rothstein, H.R. (2009). Introduction to Meta-Analysis. A John Wiley and Sons, West Sussex.

Borrell, B. (2015). NSF investigation of high-profile plant retractions ends in two debarments. Available at: [https://retractionwatch.com/2015/09/

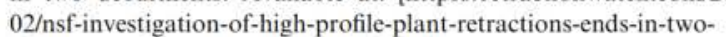
debarments/] Last accessed July 272020.

Burkner, P.C. (2017). brms: An R package for bayesian multilevel models using stan. J. Stat. Software, 80, 1-28.

Cadotte, M.W., Davies, T.J. \& Peres-Neto, P.R. (2017). Why phylogenies do not always predict ecological differences. Ecol. Monog., 87, 535-551.

Callaway, R.M. \& Aschehoug, E.T. (2000). Invasive plants versus their new and old neighbors: a mechanism for exotic invasion. Science, 290, $521-523$.

Callaway, R.M. \& Ridenour, W.M. (2004). Novel weapons: invasive success and the evolution of increased competitive ability. Front. Ecol. Envir., 2, 436-443.

Cayuela, L., Stein, A. \& Oksanen, J. (2017). Taxonstand: taxonomic standardization of plant species names. $\mathrm{R}$ package version 2.0. R Foundation for Statistical Computing.

Chave, J., Navarrete, D., Almeida, S., Alvarez, E., Aragao, L.E.O.C., Bonal, D., et al. (2010). Regional and seasonal patterns of litterfall in tropical South America. Biogeosciences, 7, 43-55.

Cheng, F. \& Cheng, Z. (2015). Research progress on the use of plant allelopathy in agriculture and the physiological and ecological mechanisms of allelopathy. Front. Plant Sci., 6, 1020.

Corbett, B.F. \& Morrison, J.A. (2012). The allelopathic potentials of the non-native invasive plant Microstegium vimineum and the Native Ageratina altissima: Two dominant species of the eastern forest herb layer. Northeast. Nat, 19, 297-312.

Cummings, J.A., Parker, I.M. \& Gilbert, G.S. (2012). Allelopathy: a tool for weed management in forest restoration. Plant Ecol., 213, 1975-1989.

Darwin, C. (1859). On the Origin of Species. J. Murrary, London.

Del Fabbro, C. \& Prati, D. (2015). Invasive plant species do not create more negative soil conditions for other plants than natives. Persp. Plant Ecol. Evol. System., 17, 87-95. 
Egger, M., Davey Smith, G., Schneider, M. \& Minder, C. (1997). Bias in meta-analysis detected by a simple, graphical test. BMJ, 315, 629-634.

Facelli, J.M. \& Carson, W.P. (1991). Heterogeneity of plant litter accumulation in successional communities. Bulletin Torrey Botanical Club, 118, 62-66.

Fukami, T., Martijn Bezemer, T., Mortimer, S.R. \& Putten, W.H. (2005). Species divergence and trait convergence in experimental plant community assembly. Ecol. Lett., 8, 1283-1290.

Grainger, T.N., Levine, J.M. \& Gilbert, B. (2019). The invasion criterion: A common currency for ecological research. Trends Ecol Evol, 34, 925-935.

Gruntman, M., Zieger, S. \& Tielborger, K. (2016). Invasive success and the evolution of enhanced weaponry. Oikos, 125, 59-65.

Grutters, B.M.C., Saccomanno, B., Gross, E.M., Van de Waal, D.B., van

Donk, E. \& Bakker, E.S. (2017). Growth strategy, phylogeny and stoichiometry determine the allelopathic potential of native and nonnative plants. Oikos, 126, 1770-1779.

Gurevitch, J., Koricheva, J., Nakagawa, S. \& Stewart, G. (2018). Metaanalysis and the science of research synthesis. Nature, 555, 175-182.

Heisey, R.M. (1990). Evidence for allelopathy by tree-of-heaven (Ailanthus altissima). J. Chem. Ecol., 16, 2039-2055.

Hierro, J.L. \& Callaway, R.M. (2003). Allelopathy and exotic plant invasion. Plant Soil, 256, 29-39.

Hort, A. (1916). Theophrastus: Enquiry into plants and minor works on odours and weather signs, with an English translation by Sir Arthur Hort, bart. W. Heinemann, London.

Huang, R., O'Donnell, A.J., Barboline, J.J. \& Barkman, T.J. (2016), Convergent evolution of caffeine in plants by co-option of exapted ancestral enzymes. Proc. Natl Acad. Sci. USA, 113, 10613-10618.

Jackson, J.R. \& Willemsen, R.W. (1976). Allelopathy in the first stages of secondary succession on the piedmont of New Jersey. Am. J. Bot, 63 , $1015-1023$.

Jose, S. \& Gillespie, A.R. (1998). Allelopathy in black walnut (Juglans nigraL.) alley cropping. II. Effects of juglone on hydroponically grown corn (Zea mays L.) and soybean (Glycine maxL. Merr.) growth and physiology. Plant Soil, 203, 199-206.

Kattge, J., Bonisch, G., Diaz, S., Lavorel, S., Prentice, I.C., Leadley, P., et al. (2020). TRY plant trait database - enhanced coverage and open access. Glob. Chang. Biol., 26, 119-188.

Kleyer, M., Bekker, R.M., Knevel, I.C., Bakker, J.P., Thompson, K., Sonnenschein, M., et al. (2008). The LEDA traitbase: a database of life-history traits of the Northwest European flora. J. Ecol., 96, $1266-1274$.

Lankau, R. (2009). Soil microbial communities alter allelopathic competition between Alliaria petiolata and a native species. Biol. Invasions, 12, 2059-2068.

Lankau, R.A. \& Kliebenstein, D.J. (2009). Competition, herbivory and genetics interact to determine the accumulation and fitness consequences of a defence metabolite. J. Ecol., 97, 78-88.

Lau, J.A., Puliafico, K.P., Kopshever, J.A., Steltzer, H., Jarvis, E.P., Schwarzlander, M., et al. (2008). Inference of allelopathy is complicated by effects of activated carbon on plant growth. New Phytol., 178. $412-423$.

Lekberg, Y., Bever, J.D., Bunn, R.A., Callaway, R.M., Hart, M.M., Kivlin, S.N., et al. (2018). Relative importance of competition and plant-soil feedback, their synergy, context dependency and implications for coexistence. Ecol. Lett., 21, 1268-1281.

Li, Y.P., Feng, Y.L., Kang, Z.L., Zheng, Y.L., Zhang, J.L. \& Chen, Y.J. (2017). Changes in soil microbial communities due to biological invasions can reduce allelopathic effects. J. Applied Ecol., 54, 1281-1290.

Liu, H. \& Stiling, P. (2006). Testing the enemy release hypothesis: a review and meta-analysis. Biol. Invasions, 8, 1535-1545.

Lynch, M. (1991). Methods for the analysis of comparative data in evolutionary biology. Evolution, 45, 1065-1080.

Mahall, B.E. \& Callaway, R.M. (1992). Root Communication mechanisms and intracommunity distributions of 2 Mojave desert shrubs. Ecology, 73, 2145-2151.
Malecore, E.M., Dawson, W., Kempel, A., Muller, G. \& van Kleunen, M. (2019). Nonlinear effects of phylogenetic distance on early-stage establishment of experimentally introduced plants in grassland communities. J. Ecol., 107, 781-793.

Martín, M.Á., Reyes, M. \& Taguas, F.J. (2017). Estimating soil bulk density with information metrics of soil texture. Geoderma, 287, 66-70.

Meiners, S.J., Kong, C.-H., Ladwig, L.M., Pisula, N.L. \& Lang, K.A. (2012). Developing an ecological context for allelopathy. Plant Ecol., 213, 1221-1227.

Mishra, S., Upadhyay, R.S. \& Nautiyal, C.S. (2013). Unravelling the beneficial role of microbial contributors in reducing the allelopathic effects of weeds. Appl. Microbiol. Biotechnol., 97, 5659-5668.

Molisch, H. (1937). Der Einfluss einer Pflanze auf die andere. Allelopathie, Fischer Jena.

Myster, R.W. \& Pickett, S.T.A. (1992). Dynamics of associations between plants in ten old fields during 31 years of succession. J. Ecol., 80, 291-302.

Nakagawa, S. \& Santos, E.S.A. (2012). Methodological issues and advances in biological meta-analysis. Evol. Ecol., 26, 1253-1274.

Ning, L., Yu, F.-H. \& van Kleunen, M. (2016). Allelopathy of a native grassland community as a potential mechanism of resistance against invasion by introduced plants. Biol. Invasions, 18, 3481-3493.

Oduor, A.M., van Kleunen, M. \& Stift, M. (2020). Allelopathic effects of Brassica nigra in both its native and invasive ranges do not support the novel-weapons hypothesis. Am. J. Botany, 107, 1106-1113.

Overholt, W.A., Cuda, J.P. \& Markle, L. (2012). Can novel weapons favor native plants? Allelopathic interactions between Morella cerifera $(\mathrm{L}$.$) and$ Schinus terebinthifolia Raddil. J. Torrey Botanical Soc., 139, 356-366.

Pagel, M. (1999). Inferring the historical patterns of biological evolution. Nature, 401, 877-884.

Palus, S. (2016). Sample tampering leads to plant scientist's 7 th retraction. Available at: [https://retractionwatch.com/2016/03/03/sample-tamperingleads-to-plant-scientists-7th-retraction/] Last accessed July 272020.

Paradis, E. \& Schliep, K. (2018). ape 5.0: an environment for modern phylogenetics and evolutionary analyses in R. Bioinformatics, 35, 526-528.

Parepa, M. \& Bossdorf, O. (2016). Testing for allelopathy in invasive plants: it all depends on the substrate! Biol. Invasions, 18, 2975-2982.

Perry, L.G., Thelen, G.C., Ridenour, W.M., Callaway, R.M., Paschke, M.W. \& Vivanco, J.M. (2007). Concentrations of the Allelochemical ( \pm )-Catechin IN Centaurea maculosa Soils. J. Chem. Ecol., 33, 2337-2344.

Pichersky, E. \& Lewinsohn, E. (2011). Convergent evolution in plant specialized metabolism. Ann. Review Plant Biol., 62, 549-566.

Prati, D. \& Bossdorf, O. (2004). Allelopathic inhibition of germination by Alliaria petiolata (Brassicaceae). Am. J. Bot., 91, 285-288.

Qian, H. \& Jin, Y. (2015). An updated megaphylogeny of plants, a tool for generating plant phylogenies and an analysis of phylogenetic community structure. J. Plant Ecol., 9, 233-239.

$\mathrm{R}$ Core Team (2019). R: A language and environment for statistical computing. R Foundation for Statistical Computing Vienna, Austria. Available at: http://www.R-project.org/.

Rabotnov, T.J.S.J.o.E. (1981). Importance of the evolutionary approach to the study of allelopathy [Plants].

Reich, P.B., Hobbie, S.E., Lee, T.D. \& Pastore, M.A. (2018). Unexpected reversal of $\mathrm{C} 3$ versus $\mathrm{C} 4$ grass response to elevated $\mathrm{CO} 2$ during a 20year field experiment. 360, 317-320.

Rice, E.L. (1974). Allelopathy, 1st edn. New York, NY: Academic press.

Rice, E.L. (1984). Allelopathy, 2nd edn. New York, NY: Academic press.

Richardson, D.M., Pyšek, P., Rejmánek, M., Barbour, M.G., Panetta, F.D. \& West, C.J. (2000). Naturalization and invasion of alien plants: concepts and definitions. Divers. Distrib., 6, 93-107.

Rosenthal, R. (1979). The file drawer problem and tolerance for null results. Psychol. Bull., 86, 638-641.

San Emeterio, L., Arroyo, A. \& Canals, R.M. (2004). Allelopathic potential of Lolium rigidum Gaud on the early growth of three associated pasture species. Grass Forage Sci., 59, 107-112. 
Saul, W.C. \& Jeschke, J.M. (2015). Eco-evolutionary experience in novel species interactions. Ecol. Lett., 18, 236-245.

Schielzeth, H. (2010). Simple means to improve the interpretability of regression coefficients. Methods Ecol. Evol., 1, 103-113.

Sera, B. (2012). Effects of soil substrate contaminated by knotweed leaves on seed development. Pol. J. Environ. Stud., 21, 713-717.

Simberloff, D. \& Von Holle, B. (1999). Positive interactions of nonindigenous species: Invasional meltdown? Biol. Invasions, 1, 21-32.

Stinson, K.A., Campbell, S.A., Powell, J.R., Wolfe, B.E., Callaway, R.M. Thelen, G.C., et al. (2006). Invasive plant suppresses the growth of native tree seedlings by disrupting belowground mutualisms. PLoS Biol., 4, e140.

Tharayil, N., Bhowmik, P., Alpert, P., Walker, E., Amarasiriwardena, D. \& Xing, B. (2009). Dual purpose secondary compounds: phytotoxin of Centaurea diffusa also facilitates nutrient uptake. New Phytol., 181, $424-434$.

Thuiller, W., Gallien, L., Boulangeat, I., de Bello, F., Munkemuller, T., Roquet, C., et al. (2010). Resolving Darwin's naturalization conundrum: a quest for evidence. Divers. Distrib., 16, 461-475.

Trikalinos, T.A. \& Ioannidis, J.P. (2005). Assessing the evolution of effect sizes over time. In Publication Bias in Meta-Analysis (eds Rothstein. H.R., Sutton, A.J. \& Borenstein, M.) Chichester: John Wiley \& Sons Ltd. 241-260.

Turcotte, M.M., Thomsen, C.J.M., Broadhead, G.T., Fine, P.V.A., Godfrey, R.M., Lamarre, G.P.A., et al. (2014). Percentage leaf herbivory across vascular plant species. Ecology, 95, 788.

Uesugi, A. \& Kessler, A. (2013). Herbivore exclusion drives the evolution of plant competitiveness via increased allelopathy. New Phytol., 198, 916-924.

van Kleunen, M., Pysek, P., Dawson, W., Essl, F., Kreft, H., Pergl, J., et al. (2019). The global naturalized alien flora (GloNAF) database. Ecology, 100, e02542.

Vehtari, A., Gelman, A. \& Gabry, J. (2016). Practical Bayesian model evaluation using leave-one-out cross-validation and WAIC. Statistics and Computing, 27, 1413-1432.

Wardle, D.A., Nilsson, M.C., Gallet, C. \& Zackrisson, O. (1998). An ecosystem-level perspective of allelopathy, Biological Reviews, 73, 305-319.

Wiersema, J.H. \& León, B. (2013). World Economic Plants: A Standard Reference. Boca Raton, FL: CRC Press.

Wink, M. (2003). Evolution of secondary metabolites from an ecological and molecular phylogenetic perspective. Phytochemistry, 64, 3-19.
Wise, K., Gill, H. \& Selby-Pham, J. (2020). Willow bark extract and the biostimulant complex Root Nectar ${ }^{\oplus}$ increase propagation efficiency in chrysanthemum and lavender cuttings. Sci. Hortic-Amsterdam, 263, 109108.

Wu, J.R., Peng, S.L., Zhao, H.B. \& Xiao, H.L. (2008). Allelopathic effects of Wedelia trilobata residues on lettuce germination and seedling growth. Allelopathy J., 22, 197-203.

Yu, F., Akin-Fajiye, M., Thapa Magar, K., Ren, J. \& Gurevitch, J. (2016). A global systematic review of ecological field studies on two major invasive plant species, Ageratina adenophora and Chromolaena odorata. Divers. Distrib., 22, 1174-1185.

Zanne, A.E., Tank, D.C., Cornwell, W.K., Eastman, J.M., Smith, S.A. FitzJohn, R.G., et al. (2014). Three keys to the radiation of angiosperms into freezing environments. Nature, 506, 89-92.

Zhang, Y.J., Tang, S.M., Liu, K.S., Li, X.F., Huang, D. \& Wang, K. (2015). The allelopathic effect of Potentilla acaulis on the changes of plant community in grassland, northern China. Ecol. Res., 30, 41-47.

Zhang, Z., Deng, L.L., Wang, L.C., Liu, J., Li, D. \& Liu, Y.J. (2018). Allelopathic potential of Phragmites australis extracts on the growth of invasive plant Alternanthera philoxeroides. Allelopathy J., 45, 55-64.

Zheng, Y.L., Feng, Y.L., Zhang, L.K., Callaway, R.M., Valiente-Banuet, A., Luo, D.Q., et al. (2015). Integrating novel chemical weapons and evolutionarily increased competitive ability in success of a tropical invader. New Phytol., 205, 1350-1359.

Zhu, X., Zhang, J. \& Ma, K. (2011). Soil biota reduce allelopathic effects of the invasive Eupatorium adenophorum. PLoS One, 6, e25393. 